\title{
Analytical and Approximate Solutions to the Fee Vibration of Strongly Nonlinear Oscillators
}

\author{
Taher A. Nofal ${ }^{1}$, Gamal M. Ismail ${ }^{2 *}$, Amal Ali M. Mady ${ }^{1}$, Sayed Abdel-Khalek $^{1}$ \\ ${ }^{1}$ Department of Mathematics, Faculty of Science, Taif University, Taif, KSA; ${ }^{2}$ Department of Mathematics, Faculty of Science, So- \\ hag University, Sohag, Egypt. \\ Email: nofal_ta@yahoo.com, *gamalm2010@yahoo.com
}

Received July $14^{\text {th }}, 2013$; revised August $15^{\text {th }}, 2013$; accepted September $17^{\text {th }}, 2013$

Copyright (C) 2013 Taher A. Nofal et al. This is an open access article distributed under the Creative Commons Attribution License, which permits unrestricted use, distribution, and reproduction in any medium, provided the original work is properly cited.

\begin{abstract}
In this paper, we implement a new approach coupled with the iteration method. This procedure is obtained by combining He's frequency-amplitude formulation and He's energy balance method into a new iteration procedure such that excellent approximate analytical solutions, valid for small as well as large values of amplitude, can be determined for nonlinear oscillators. This study has clarified the motion equation of nonlinear oscillators by the iteration method to obtain the relationship between amplitude and angular frequency. We compare the approximate periods obtained by our procedure with the numerical solution and with other methods like energy balance method and variational iteration method. The results show that the approximations are of extreme accuracy.
\end{abstract}

Keywords: Periodic Solution; Nonlinear Oscillators; Energy Balance Method; Variational Iteration Method

\section{Introduction}

Nonlinear oscillations problem is important in the physical science, mechanical structures and other kind of mathematical sciences. Most of real systems are modeled by nonlinear differential equations which are important issues in mechanical structures, mathematical physics and engineering. Recently, much attention has been focused on the properties to solve nonlinear equations in mechanical systems. In this way, some kind of these methods like Harmonic balance method (HBM) [1], Newton harmonic balance method (NHBM) [2], Frequency-amplitude formulation (FAF) [3-5], Energy balance method (EBM) [6,7], Variational iteration method (VIM) [8,9], Homotopy perturbation method (HPM) [1012], Homotopy analysis method (HAM) [13], and MaxMin method (MMA) [14,15] are introduced for nonlinear oscillatory systems.

Our main aim in this paper is to apply a new approach coupled with the iteration method by combining He's FAF and He's EBM. We compare the numerical solution with others methods like energy balance method and variational iteration method. We examine accuracy of the approximation methods.

\footnotetext{
${ }^{*}$ Corresponding author.
}

\section{Solution Procedure}

We consider a generalized nonlinear oscillator in the form:

$$
\ddot{u}+f(u, \dot{u}, \ddot{u})=0,
$$

under the initial conditions:

$$
u(0)=A, \quad \dot{u}(0)=0 .
$$

Based on He's frequency-amplitude formulation approach $[3,4]$. The trial function to determine the angular frequency $\omega$ is given by

$$
u=A \cos \omega t,
$$

substituting from Equation (3) into Equation (1), one can obtain the following residual as

$$
R(t)=-A \omega^{2} \cos \omega t+f\left(A \cos \omega t,-A \omega \sin \omega t,-A \omega^{2} \cos \omega t\right) .
$$

Introducing a new function, $H(t)$, defined as [6]

$$
H(t)=\int_{0}^{T} R(t) \cos (\omega t) \mathrm{d} t=0, \quad T=\frac{2 \pi}{\omega} .
$$

Solving the above equation, the relationship between the amplitude and frequency of the oscillator can be ob- 
tained:

\section{Applications}

In this section, some practical examples for some strongly nonlinear vibration system are illustrated to show the applicability, accuracy and effectiveness of the present method.

\subsection{Autonomous Conservative Oscillator}

It is known that the free vibrations of an autonomous conservative oscillator with inertia and static type fifthorder non-linearities is expressed by $[7,16,17]$.

$$
\begin{aligned}
& \frac{\mathrm{d}^{2} u}{\mathrm{~d} t^{2}}+\lambda u+\varepsilon_{1} u^{2} \frac{\mathrm{d}^{2} u}{\mathrm{~d} t^{2}}+\varepsilon_{1} u\left(\frac{\mathrm{d} u}{\mathrm{~d} t}\right)^{2}+\varepsilon_{2} u^{4} \frac{\mathrm{d}^{2} u}{\mathrm{~d} t^{2}} \\
& +2 \varepsilon_{2} u^{3}\left(\frac{\mathrm{d} u}{\mathrm{~d} t}\right)^{2}+\varepsilon_{3} u^{3}+\varepsilon_{4} u^{5}=0 .
\end{aligned}
$$

The initial conditions for Equation (6) are given by $u(0)=A$ and $\mathrm{d} u / \mathrm{d} t=0$, where $A$ represents amplitude of the oscillation.

Motion is assumed to start from the position of maximum displacement with zero initial velocity $\lambda$ is an integer which may take values of $\lambda=1,0$ or -1 , and $\varepsilon_{1}$, $\varepsilon_{2}, \varepsilon_{3}$ and $\varepsilon_{4}$ are positive parameters in Table 1.

By using the following trial function to determine the angular frequency $\omega$ :

$$
u=A \cos \omega t .
$$

Substituting the above trial functions into Equation (6) results in, the following residual

$$
\begin{aligned}
R(t)= & \frac{A}{16}\left[\left(12 A^{2} \varepsilon_{3}+10 A^{4} \varepsilon_{4}+16 \lambda-16 \omega^{2}-8 A^{2} \varepsilon_{1} \omega^{2}\right.\right. \\
& \left.-6 A^{4} \varepsilon_{2} \omega^{2}\right) \cos \omega t+\left(4 A^{2} \varepsilon_{3}+5 A^{4} \varepsilon_{4}-8 A^{2} \varepsilon_{1} \omega^{2}\right. \\
& \left.\left.-7 A^{4} \varepsilon_{2} \omega^{2}\right) \cos 3 \omega t+\left(A^{4} \varepsilon_{4}-3 A^{4} \varepsilon_{2} \omega^{2}\right) \cos 5 \omega t\right] .
\end{aligned}
$$

Using Equation (8) into Equation (5), we can easily obtain

$$
\begin{aligned}
& H(t)=\int_{0}^{2 \pi / \omega} R(t) \cos \omega t \mathrm{~d} t \\
& =\frac{A \pi}{8 \omega}\left[6 \varepsilon_{3} A^{2}+5 \varepsilon_{4} A^{4}+8 \lambda-\left(8+4 \varepsilon_{1} A^{2}+4 \varepsilon_{2} A^{4}\right) \omega^{2}\right]=0 .
\end{aligned}
$$

Solving the above equation, an approximate frequency $\omega$ as a function of amplitude $A$ as follow:

$$
\omega=\sqrt{\frac{6 A^{2} \varepsilon_{3}+5 A^{4} \varepsilon_{4}+8 \lambda}{8+4 A^{2} \varepsilon_{1}+3 A^{4} \varepsilon_{2}}} .
$$

Hence, the approximate solution can be readily obtained
Table 1. Values of dimensionless parameters $\varepsilon_{i}$ in Equation (6) for four models [16].

\begin{tabular}{ccccc}
\hline Mode & $\varepsilon_{1}$ & $\varepsilon_{2}$ & $\varepsilon_{3}$ & $\varepsilon_{4}$ \\
\hline 1 & 0.326845 & 0.129579 & 0.232598 & 0.087584 \\
2 & 1.642033 & 0.913055 & 0.313561 & 0.204297 \\
3 & 4.051486 & 1.665232 & 0.281418 & 0.149677 \\
4 & 8.205578 & 3.145368 & 0.272313 & 0.133708 \\
\hline \multicolumn{5}{c}{$u(t)=A \cos \left(\sqrt{\frac{6 A^{2} \varepsilon_{3}+5 A^{4} \varepsilon_{4}+8 \lambda}{8+4 A^{2} \varepsilon_{1}+3 A^{4} \varepsilon_{2}}} t\right)}$.
\end{tabular}

Mehdipour et al. [7] obtained the approximate frequency for Equation (6) by the energy balance method

$$
\omega_{E B M}=\frac{\sqrt{3}}{3} \sqrt{\frac{12 \lambda+9 \varepsilon_{3} A^{2}+7 \varepsilon_{4} A^{4}}{4+2 \varepsilon_{1} A^{2}+\varepsilon_{2} A^{4}}} .
$$

The values of dimensionless parameters $\varepsilon_{1}, \varepsilon_{2}, \varepsilon_{3}$ and $\varepsilon_{4}$ associated with each of the four calculation modes are shown in Table 2 [7].

Additionally, the comparison between these methodologies can be found in Table 2 and Figure 1. It has been shown that the results of analytical approximate solution are in good agreement with those obtained from the results of energy balance method [7], and with an accurate numerical solution using fourth-order Runge-Kutta method (R-K) as shown in Table 2 and Figure 1.

\subsection{Tapered Beams}

Tapered beams is an important model for engineering structures which require a variable stiffness along the length, such as moving arms and turbine blades [18-20]. In dimensionless form, the governing differential equation corresponding to fundamental vibration mode of a tapered beam is given by [20].

$$
\begin{aligned}
& \left(\frac{\mathrm{d}^{2} u}{\mathrm{~d} t^{2}}\right)+u+\varepsilon_{1}\left(u^{2}\left(\frac{\mathrm{d}^{2} u}{\mathrm{~d} t^{2}}\right)+u\left(\frac{\mathrm{d} u}{\mathrm{~d} t}\right)^{2}\right) \\
& +\varepsilon_{2} u^{3}=0, u(0)=A, \frac{\mathrm{d} u}{\mathrm{~d} t}=0 .
\end{aligned}
$$

Assume that the solution can be expressed as: $u(t)=$ $A \cos \omega t$.

Similarly, substituting the trial solution into Equation (13), this leads to the following residual

$$
\begin{aligned}
R(t)= & \frac{A}{4}\left(4+3 \varepsilon_{2} A^{2}-4 \omega^{2}-2 \varepsilon_{1} \omega^{2} A^{2}\right) \cos \omega t \\
& +\frac{A^{3}}{4}\left(\varepsilon_{2}-2 \varepsilon_{1} \omega^{2}\right) \cos 3 \omega t .
\end{aligned}
$$

Using Equation (14) into Equation (5) we can easily obtain 
Table 2. The comparison between energy balance method [7] and analytical approximate solution for four modes (1 4) $(\lambda=1)$.

\begin{tabular}{|c|c|c|c|c|c|c|c|c|}
\hline & \multicolumn{2}{|c|}{ Mode 1} & \multicolumn{2}{|c|}{ Mode 2} & \multicolumn{2}{|c|}{ Mode 3} & \multicolumn{2}{|c|}{ Mode 4} \\
\hline A & $\omega[7]$ & $\omega$ & $\omega[7]$ & $\omega$ & $\omega[7]$ & $\omega$ & $\omega[7]$ & $\omega$ \\
\hline
\end{tabular}

$\begin{array}{lllllllll}0.01 & 1.0000 & 1.0000 & 0.9999 & 0.9999 & 0.9999 & 0.9999 & 0.9998 & 0.9998\end{array}$

$\begin{array}{lllllllll}0.1 & 1.0001 & 1.0001 & 0.9971 & 0.9911 & 0.9911 & 0.9910 & 0.9810 & 0.9810\end{array}$

$\begin{array}{lllllllll}0.5 & 1.0019 & 1.0015 & 0.9350 & 0.8309 & 0.8309 & 0.8278 & 0.7134 & 0.7093\end{array}$

$\begin{array}{lllllllll}1 & 1.0124 & 1.0071 & 0.8129 & 0.6142 & 0.6142 & 0.5978 & 0.4666 & 0.4528\end{array}$

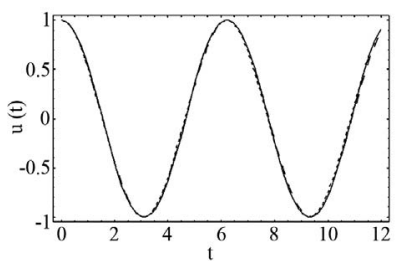

(a)

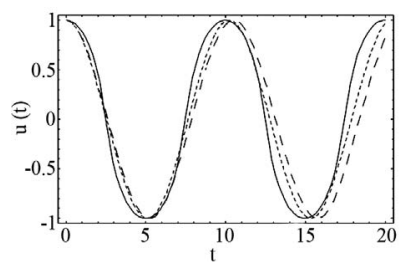

(c)

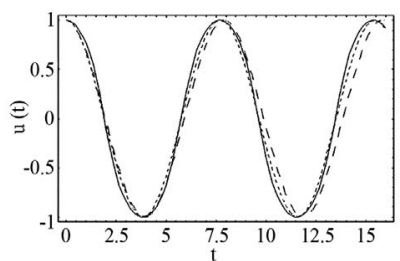

(b)

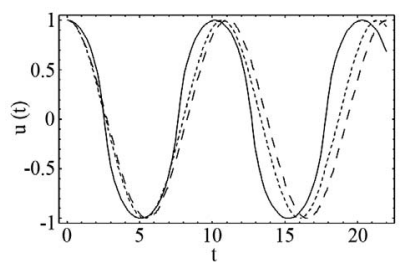

(d)
Figure 1. The comparison between EBM solution (.....), analytical approximate solution (- - -) and numerical solution, solved by the Runge-Kutta method of order 4 (-) for four modes $(\lambda=1, A=1)$.

$$
\begin{aligned}
H(t) & =\int_{0}^{2 \pi / \omega} R(t) \cos \omega t \mathrm{~d} t \\
& =\frac{A \pi}{4 \omega}\left[4+3 \varepsilon_{2} A^{2}-2\left(2+\varepsilon_{1} A^{2}\right) \omega^{2}\right]=0 .
\end{aligned}
$$

Solving the above equation, an approximate frequency as a function of amplitude equals:

$$
\omega^{2}=\frac{4+3 \varepsilon_{2} A^{2}}{4+2 \varepsilon_{1} A^{2}}
$$

which is the same as given by Hoseini et al. [20].

Hence, the approximate solution can be readily obtained

$$
u(t)=A \cos \left(\sqrt{\frac{4+3 \varepsilon_{2} A^{2}}{4+2 \varepsilon_{1} A^{2}}} t\right) .
$$

To illustrate the validity of the analytical approximate solution for this example, the results are compared with the variational iteration method [21] and with an accurate numerical solution, using fourth-order Runge-Kutta method (R-K) in Figure 2.

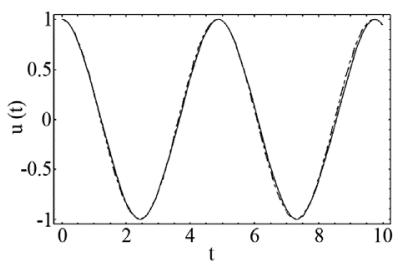

(a)

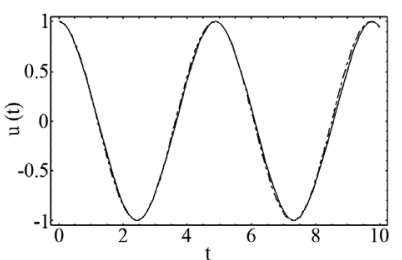

(c)

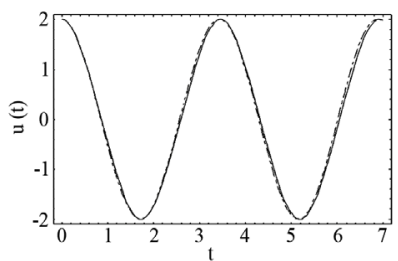

(b)

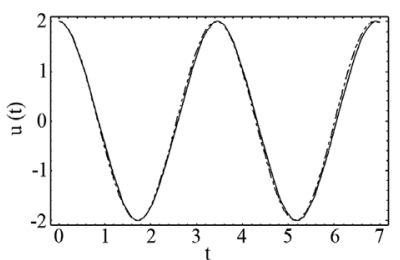

(d)
Figure 2. The comparison between variational iteration method (....), analytical approximate solution (- - -) and numerical solution, solved by the Runge-Kutta method of order 4 (-). (a) $\varepsilon_{1}=0.1, \varepsilon_{2}=1, A=1$; (b) $\varepsilon_{1}=0.1, \varepsilon_{2}=1, A=2$; (c) $\varepsilon_{1}=1, \varepsilon_{2}=2, A=1$; (d) $\varepsilon_{1}=1, \varepsilon_{2}=1, A=1$.

\subsection{Motion of the Particle on Arrange Parabola}

The governing equation of motion and initial conditions can be expressed as [5,22-24].

$$
\left(1+4 q^{2} u^{2}\right) \frac{\mathrm{d}^{2} u}{\mathrm{~d} t^{2}}+4 q^{2} u\left(\frac{\mathrm{d} u}{\mathrm{~d} t}\right)^{2}+\Delta u=0, u(0)=A, \frac{\mathrm{d} u}{\mathrm{~d} t}=0,
$$

where $q>0$ and $\Delta>0$ are known positive constants. We choose trial function $u(t)=A \cos \omega t$, where $\omega$ is assumed to be the frequency of the nonlinear oscillator.

Similar to previous examples we have

$$
R(t)=\left(\Delta A-A \omega^{2}-2 A^{3} q^{2} \omega^{2}\right) \cos \omega t-2 A^{3} q^{2} \omega^{2} \cos 3 \omega t .
$$

Finally, the frequency amplitude relationship can be obtained as:

$$
\omega^{2}=\frac{\Delta}{1+2 A^{2} q^{2}}
$$

which is the same as given by Davodi et al. [5]. Hence, the approximate solution can be obtained as

$$
u(t)=A \cos \left(\sqrt{\frac{\Delta}{1+2 A^{2} q^{2}}} t\right) .
$$

For this following value of parameters the numerical results are compared with EBM [5] and fourth-order Runge-Kutta method (R-K) as shown in Figure 3.

\section{Conclusion}

The methods to find analytical approximate solutions for nonlinear vibrating equations are not closed, which have important application in physical sciences and engineer- 


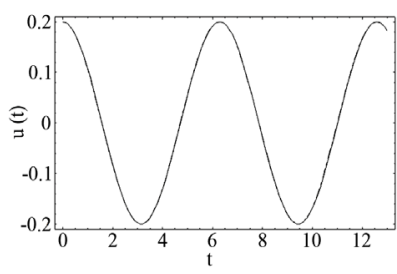

(a)

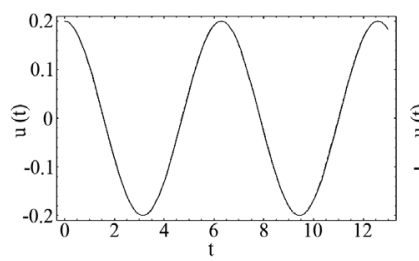

(c)

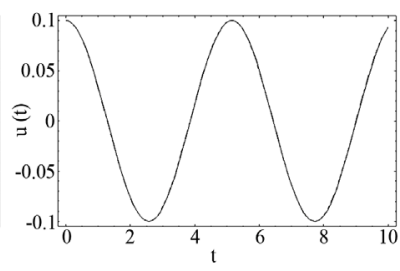

(b)

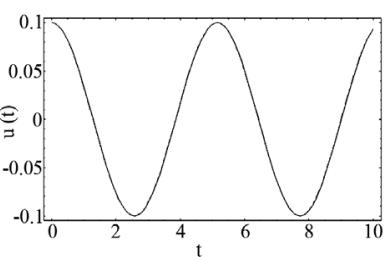

(d)
Figure 3. The comparison between EBM solution (- - -), analytical approximate solution (....) and numerical solution, solved by the Runge-Kutta method of order 4 (-). (a) $\Delta=1$, $q=0.2, A=0.2 ;$ (b) $\Delta=1.5, q=0.6, A=0.1 ;$ (c) $\Delta=1, q=2$, $A=1 ;$ (d) $\Delta=1, q=1, A=1$.

ing. In this way, we illustrated that the present method is very effective and convenient and does not require linearization or small perturbation. The obtained analytical solutions were compared with those calculated by the energy balance method and variational iteration method. The obtained results are valid for the whole solution domain with high accuracy. In comparison to fourth-order Runge-Kutta method, which is powerful numerical solution, the results show that the present method is very convenient for solving nonlinear equations and also can be used for strong nonlinear oscillators.

\section{REFERENCES}

[1] M. Ghadimi and H. D. Kaliji, "Application of the Harmonic Balance Method on Nonlinear Equations," World Applied Sciences Journal, Vol. 22, No. 4, 2013, pp. 532-537.

[2] S. KLai, C. W. Lim, B. S. Wu, C. Wang, Q. C. Zeng and X. F. He, "Newton-Harmonic Balancing Approach Applications for Accurate Solutions to Nonlinear CubicQuintic Duffing Oscillators," Applied Mathematical Modeling, Vol. 33, No. 2, 2009, pp. 852-866. http://dx.doi.org/10.1016/j.apm.2007.12.012

[3] J. H. He, "Comment on He's Frequency Formulation for Nonlinear Oscillators," European Journal of Physics, Vol. 29, No. 4, 2008, pp. 19-22. http://dx.doi.org/10.1088/0143-0807/29/4/L02

[4] J. H. He, "An Improved Amplitude-Frequency Formulation for Nonlinear Oscillators," International Journal of Nonlinear Science and Numerical Simulation, Vol. 9, No. 2, 2008, pp. 211-212. http://dx.doi.org/10.1515/IJNSNS.2008.9.2.211

[5] A. G. Davodi, D. D. Gangi, R. Azami and H. Babazadeh, "Application of Improved Amplitude-Frequency Formu- lation to Nonlinear Differential Equation of Motion Equations," Modern Physics Letters B, Vol. 23, No. 28, 2009, pp. 3427-3436. http://dx.doi.org/10.1142/S0217984909021466

[6] H.-L. Zhang, "Periodic Solutions for Some Strongly Nonlinear Oscillators by He's Energy Balance Method," Computers and Mathematics with Applications, Vol. 58, No. 11-12, 2009, pp. 2423-2426. http://dx.doi.org/10.1016/j.camwa.2009.03.068

[7] I. Mehdipour, D. D. Ganji and M. Mozaffari, "Application of the Energy Balance Method to Nonlinear Vibrating Equations," Current Applied Physics, Vol. 10, No. 1, 2010, pp. 104-112.

http://dx.doi.org/10.1016/j.cap.2009.05.016

[8] J. H. He, G. C. Wu and F. Austin, "The Variational Iteration Method Which Should Be Followed," Nonlinear Science Letters A, Vol. 1, No. 1, 2010, pp. 1-30.

[9] N. Herisanu and V. Marinca, "A Modified Variational iteration Method for Strongly Nonlinear Problems," Nonlinear Science Letters A, Vol. 1, 2010, pp. 183-192.

[10] J. H. He, "A Coupling Method of a Homotopy Technique and a Perturbation Technique for Non-Linear Problems," International Journal of Non-Linear Mechanics, Vol. 35, No. 1, 2000, pp. 37-43. http://dx.doi.org/10.1016/S0020-7462(98)00085-7

[11] J. H. He, "Application of Homotopy Perturbation Method to Nonlinear Wave Equations," Chaos, Solitons and Fractals, Vol. 26, No. 3, 2005, pp. 695-700. http://dx.doi.org/10.1016/j.chaos.2005.03.006

[12] D. D. Ganji, "The Application of He's Homotopy Perturbation Method to Nonlinear Equations Arising in Heat Transfer," Physics Letters A, Vol. 355, No. 4-5, 2006, pp. 337-341. http://dx.doi.org/10.1016/j.physleta.2006.02.056

[13] A. R. Ghotbi, M. Omidvar and A. Barari, "Infiltration in Unsaturated Soils-An Analytical Approach," Computers and Geotechnics, Vol. 38, No. 6, 2011, pp. 777-782. http://dx.doi.org/10.1016/j.compgeo.2011.05.007

[14] S. S. Ganji, A. Barari and D. D. Ganji, "Approximate Analyses of Two Mass-Spring Systems and Buckling of a Column," Computers and Mathematics with Applications, Vol. 61, No. 4, 2011, pp. 1088-1095. http://dx.doi.org/10.1016/j.camwa.2010.12.059

[15] M. Ghadimi, H. D. Kaliji and A. Barari, "Analytical Solutions to Nonlinear Mechanical Oscillation Problems," Journal of Vibroengineering, Vol. 13, No. 2, 2011, pp. 133-143.

[16] S.-S. Chen and C.-K. Chen, "Application of the Differential Transformation Method to the Free Vibrations of Strongly Nonlinear Oscillators," Nonlinear analysis: Real Word Applications, Vol. 10, No. 2, 2009, pp. 881-888. http://dx.doi.org/10.1016/j.nonrwa.2005.06.010

[17] M. N. Hamden and N. H. Shabaneh, "On the Large Amplitude Free Vibrations of a Restrained Uniform Beam Carrying an Intermediate Lumped Mass," Journal of Sound and Vibration, Vol. 199, No. 5, 1997, pp. 711-736. http://dx.doi.org/10.1006/jsvi.1996.0672

[18] D. J. Goorman, "Free Vibration of Beams and Shafts," Wiley, New York, 1975. 
[19] R. C. Hibbeler, "Engineering Mechanics Dynamics," Prentice-Hall, New Jersey, 2001.

[20] S. H. Hoseini, T. Pirhodaghi, M. T. Ahmadian and G. H. Farrahi, "On the Large Amplitude Free Vibrations of Tapered Beams: An Analytical Approach," Mechanics Research Communications, Vol. 36, No. 8, 2009, pp. 892897. http://dx.doi.org/10.1016/j.mechrescom.2009.08.003

[21] M. Ghadimi, A. Barari, H. D. Kaliji and G. Domairry, "Periodic Solutions for Highly Nonlinear Oscillation Systems," Archives of Civil and Mechanical Engineering, Vol. 12, No. 3, 2012, pp. 389-395.

http://dx.doi.org/10.1016/j.acme.2012.06.014
[22] A. H. Nayfeh and D. T. Mook, "Nonlinear Oscillations," Wiley, New York, 1979.

[23] D. D Gangi and M. Azimi, "Application of Max Min Approach and Amplitude Frequency Formulation to Nonlinear Oscillation Systems," UPB Scientific Bulletin, Series A, Vol. 74, No. 3, 2012, pp. 131-140.

[24] D. D Gangi, M. Azimi and M. Mostofi, "Energy Balance Method and Amplitude Frequency Formulation Based Simulation of Strongly Non-Linear Oscillators," Indian journal of Pure and Applied Physics, Vol. 50, No. 9, 2012, pp. 670-675. 